\title{
Morphometric Predictors of Lingual Undercut Depth in the Posterior Mandible and their Relevance to Immediate Dental Implant Insertion: Recommendations for CBCT
}

Predictores Morfométricos de la Profundidad de la «Undecurt» Lingual en la Parte Posterior de la Mandíbula y su Relevancia para la Inserción Inmediata de Implantes Dentales: Recomendaciones para la CBCT

\author{
Ashraf E AbuKaraky ${ }^{1}$; Abeer Alhadidi'; Ahmad AS Hamdan ${ }^{1}$; Manal Hamdan ${ }^{1}$ \& Firas Alsoleihat ${ }^{2}$
}

ABUKARAKY, A. E.; ALHADIDI, A.; HAMDAN, A. A. S.; HAMDAN, M. \& ALSOLEIHAT, F. Morphometric predictors of lingual undercut depth in the posterior mandible and their relevance to immediate dental implant insertion: Recommendations for CBCT. Int. J. Morphol., 37(3):947-952, 2019.

SUMMARY: Deep lingual undercut (LU) is commonly encountered in the posterior mandible, and is considered a risk factor in dental implants. In this study we investigated the value of data extracted from OPGs in predicting LU depth. Such predictors might be valuable in reducing the chance of lingual plate perforation (LPP) by recommending CBCTs prior to dental implant insertion when deep LU is anticipated We aimed at assessing the following variables as potential predictors of LU depth: 1) alveolar process height (measured on OPGs), 2) alveolar process width (measured on CBCTs), and 3) the distance from apical region of dental alveoli to superior margin of IAN canal (measured on OPGs). 128 CBCTs and corresponding OPGs of posterior mandibles of 128 patients (70 females, 58 males; age range $=18-87$ years, mean age $=45.8$ years, $\mathrm{SD}=17.0$ years) were used. Only dentate sites of lower first (LM1) and second molars $(\mathrm{LM} 2)$ were considered. Four predictors of LU depth were found, the strongest was the ratio between alveolar process width (which could be assessed clinically) and alveolar process height as measured on OPGs ( $\mathrm{r}=.454$ at LM1 site, $\mathrm{r}=.592$ at LM2 site). Predictors derived from OPG measurements might be valuable in anticipating LU depth and might be more valuable when combined with alveolar process width (which might be assessed clinically). We recommend considering the suggested predictors in assessing the need of CBCT prior to immediate dental implant insertion in posterior mandible.

KEY WORDS: Lingual undercut; Posterior mandible; Dental implants; Cone beam computed tomography; Lingual plate perforation.

\section{INTRODUCTION}

Dental implants have been optimized to achieve high success rate, thus become an integral part of dental practice. However, surgical errors during the placement of dental implants and the resultant complications still do take place (Greenstein et al., 2008a,b). The resultant complications may occur during the surgical procedure, during the healing period, or after function. These complications range from mild to severe depending on the degree of damage (Berberi et al., 1993; Givol et al., 2000; Kalpidis \& Setayesh, 2004; Annibali et al., 2009; Clark et al., 2017). Presence of lingual undercut (LU) and severe sloping of the lingual cortex have been identified as potential risks during implant surgeries involving the mandibular anterior and premolar regions (Tepper et al., 2001; Quirynen et al., 2003; Sener et al., 2018), and posterior region related to mandibular molars (Leong et al., 2011; Alrahaimi \& Venkatesh, 2017; Yoon et al., 2017).
Computer-simulated, cadaveric and retrospective studies have shown a significant risk of lingual plate perforations (LPP) related to dental implant insertion in the posterior mandibular region (Leong et al.; Huang et al., 2015; Clark et al.). As a preventive measure several authors have recommended a routine preoperative $\mathrm{CBCT}$ to avoid complications during implant surgeries in the posterior mandibular region (Huang et al.; Chrcanovic et al., 2016; Herranz-Aparicio et al., 2016; de Souza et al., 2016), since this is not a routine practice, especially for clinicians with limited education in dental three-dimensional radiography (Dau et al., 2017), it would be of significant clinical value, if data driven from OPGs can be used to assess the probability of the presence and severity of LU and therefore act as indicators for a preoperative CBCT. The use of CBCT offers great advantage when used to treatment plan implant therapy,

${ }^{1}$ Department of Oral and Maxillofacial Surgery, Oral Medicine, Oral Pathology and Periodontology, School of Dentistry, the University of Jordan, Amman, Jordan. ${ }^{2}$ Department of Conservative Dentistry, School of Dentistry, the University of Jordan. Amman, Jordan. 
and thus CBCT has been recommended by professional societies as the best modality for implant site analysis; however, there is still no international consensus on the necessity to use CBCT for every implant patient. The lack of international consensus is most probably based on variability of access to this technology and the cost of the routine use of this technology especially in countries where the government pays to dental care.

By comparing radiographic data from OPGs and CBCTs of the same patients, the authors aim to assess the potential correlations between data derived from OPGs and the presence and severity of LU on CBCTs. In particular, the authors aim to study the LU angulation in the posterior mandibular region, and its potential correlation with the alveolar process height, the distance between the apical region of the dental alveoli and the inferior alveolar nerve canal, and the bucco-lingual width of the alveolar process in the same region.

\section{MATERIAL AND METHOD}

Case selection and data acquisition. Appropriate ethical approval for this type of study was obtained from the authorized body, the Ethical Committee of Jordan University hospital/University of Jordan (reference number: $115 / 2018$ ), prior to the commencement of the study.

A cross sectional random sample of 197 cases obtained over the period 2015-2017 of all mandibular CBCTs and their corresponding OPGs taken at the Dental section of the Jordan University Hospital was investigated. CBCT

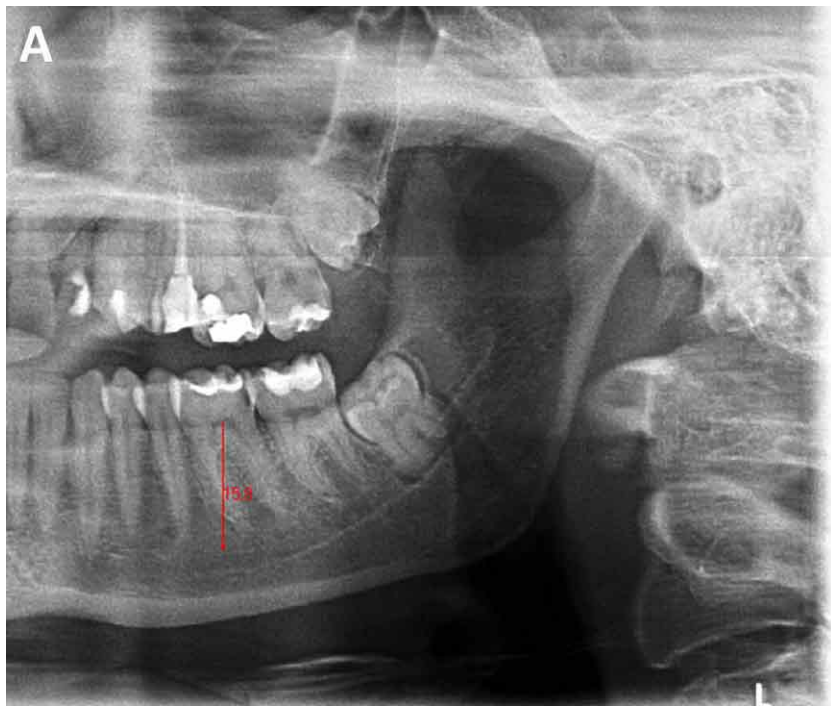

images were taken on a CS9300 scanner (Carestream health, Rochester, New York). InVivo5 Dental (Anatomage, San Jose, California) was used to view and analyze the CBCT scans. It is noteworthy to highlight that all the included CBCT scans and the OPG radiographs were already taken for clinical indications, and not for the purpose of this study.

Cases included in the sampling frame are those that met the following inclusion criteria: 1) Belong to individuals 18 years of age or older with OPG and mandibular CBCT taken within a 6 month interval, healthy with no history of serious illnesses that may adversely affect skeletal or dental development and had no previous surgeries or trauma involving the mandible. 2) The tooth should present in the target site of measurement. 3) Neither CBCT nor OPG judged distracted for any reason by any of the two observers. Medical and dental records were checked for each participant to bolster the accuracy of the selection criteria.

Measurements and data analysis. The following variables were measured on all OPG images: 1) Alveolar process height at lower first molar (LM1) and at lower second molar (LM2) sites, the alveolar process height was measured from the crest of the alveolar bone to the superior margin of the IAN canal (Fig. 1a). 2) The distance from the apical region of dental alveoli to the superior margin of the inferior alveolar nerve (IAN) canal at LM1 and at LM2 sites (Fig. 1b). All measurements on OPGs were conducted using a computercompatible OPG program.

The following variables were measured on all CBCT images: 1) LU angulation at LM1 and LM2 sites (Fig. 2a). 2) Bucco-lingual width of the alveolar process taken at the level of the alveolar crest at LM1 and LM2 sites (Fig. 2b).

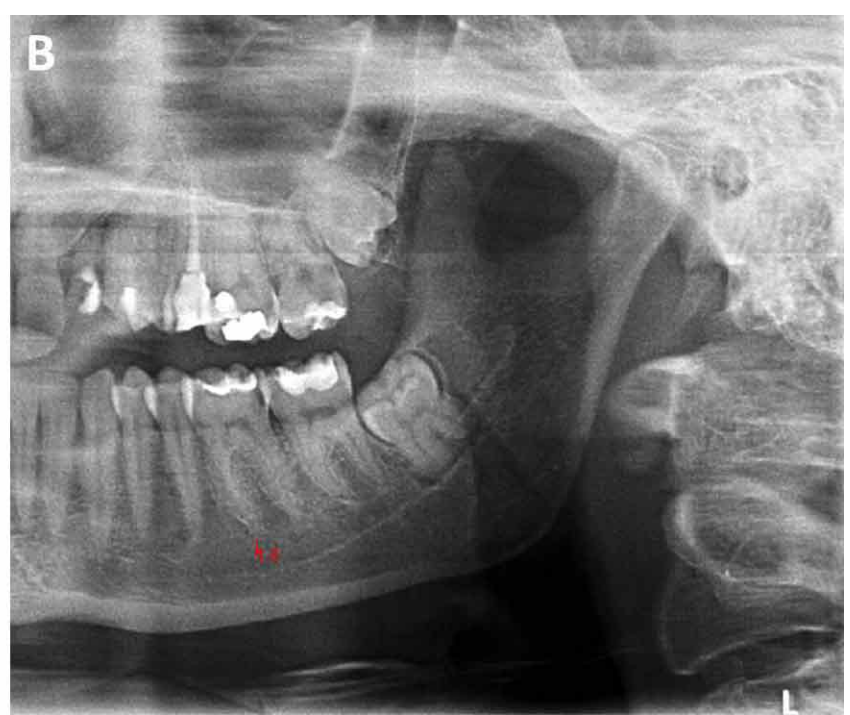

Fig. 1. Variables measured on OPG images. (a) alveolar process height, (b) the distance from the apical region of the dental alveolus to the superior margin of the IAN canal. 

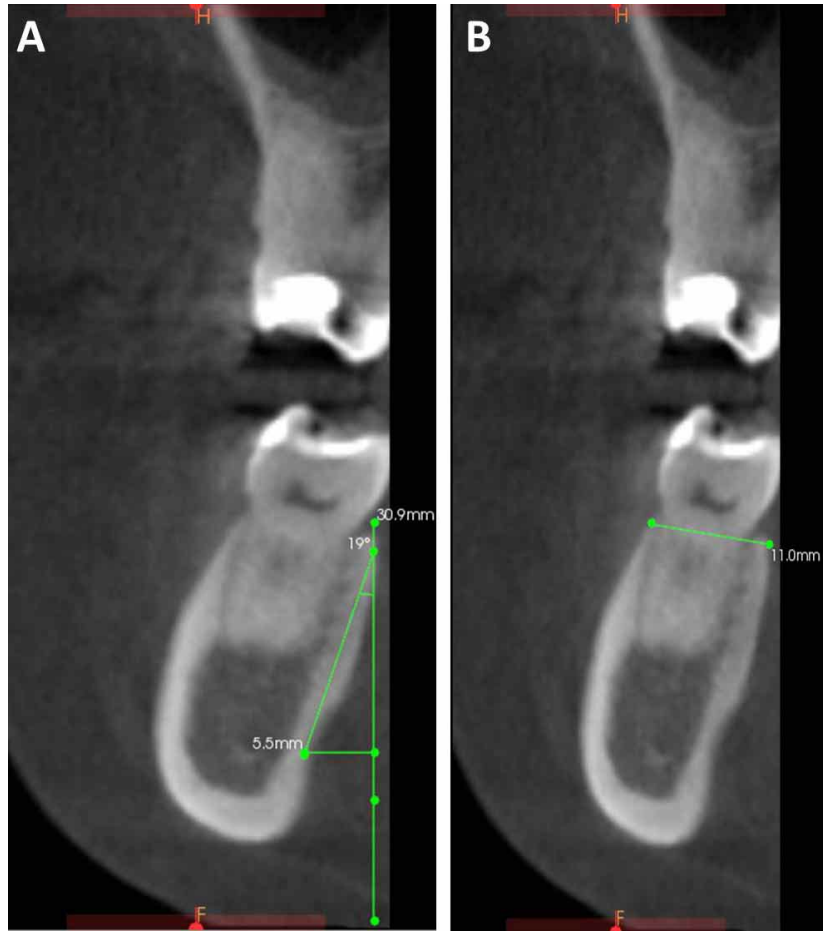

Fig. 2. Variables measured on CBCT images. (a) lingual undercut angulation, (b) bucco-lingual width of the alveolar process.

All measurements on CBCT images were conducted using a CBCT program.

It is noteworthy to mention that when the target site of measurement was bilaterally dentate, only one side was randomly chosen for measurement to avoid sample size inflation, while in case of being unilaterally dentate, the dentate side was chosen.

All measurements employed in the present investigation were carried out jointly by the two examiners (AA \& $\mathrm{MH}$ ) to eliminate errors due to inter-observer differences. Furthermore, all images used in the present study were re-measured simultaneously by the same assessors three months later. SPSS Intra-class Correlation Coefficient (ICC) statistic was used to evaluate the intra-observer reliability of the measurements conducted on these images.

Statistical analysis. Social Science Statistical Package Software (SPSS, Version 17.0, Inc., Chicago, IL) was used to analyze the data. Pearson's correlation test was used to assess the strength of the correlations between the variables considered. In accordance with Lang \& Secic (2006) absolute values of Pearson's correlation coefficient ranging between $0-0.39$ were regarded as weak, $0.40-0.59$ as moderate, 0.60 0.74 as strong, and $0.75-1$ as very strong correlation. Correlations were considered statistically significant if $\mathrm{p}$ values were less than 0.05 .
Ethics approval and consent to participate. The Ethical Committee of Jordan University Hospital/University of Jordan approved the study plan. Signed informed consent was obtained from each participant. There are no personal data in this research. All data were anonymized.

\section{RESULTS}

The ICC values for all measurements considered in the present study, which are used to assess intra-observer differences and are read as the degree of association between measurement sessions, ranged from 0.86 to 0.91 . This indicated, for all measurements considered, excellent correlation between the two measurement sessions.

Of the 197 cases obtained in the study, 128 met inclusion criteria. The selected individuals were 70 females and 58 males, age ranged from 18 to 87 years, with an average age of 45.8 years $(\mathrm{SD}=17.0)$.

The LU angulation (measured on CBCT images) was found to be: 1) moderately, conversely and statistically significantly correlated to alveolar process height (measured on OPG images) at both LM1 $(\mathrm{r}=-.403)$ and LM2 $(\mathrm{r}=-.447)$ sites (Tables I and II, respectively). 2) Weakly, conversely and statistically significantly correlated to the distance from the apical region of dental alveoli to the superior margin of the IAN canal (measured on OPG images) at both LM1 ( $\mathrm{r}=-$ .227) and LM2 (r=-.271) sites (Tables I and II, respectively). 3) Weakly, directly and statistically significantly correlated to bucco-lingual width of the alveolar mandibular process (measured on CBCT images) at both LM1 ( $\mathrm{r}=.224)$ and LM2 $(\mathrm{r}=.390)$ sites (Tables I and II, respectively). Furthermore, when the ratio between bucco-lingual width and height of the alveolar process is considered, it was found to be more strongly correlated to the lingual undercut angulation at both LM1 ( $\mathrm{r}=.454)$ and LM2 ( $\mathrm{r}=.592)$ sites (Tables I and II, respectively). Therefore, the strongest predictor for the degree of LU angulation was found to be the ratio between bucco-lingual width and height of the alveolar process at both LM1 and LM2 sites.

Based on the statistical standpoint (Lang \& Secic), the outcomes of the current study could be explained and utilized as follows: 1$) 20.6 \%(\mathrm{r} 2=0.206)$ and $35 \%\left(\mathrm{r}^{2}=0.350\right)$ of variation in LU angulation is explained by variation in the ratio between the alveolar process width and height at LM1 and LM2 site, respectively. This also means that if the value of this ratio at the LM1 site was found to be more than percentile 79.4 (100-20.6) which is equivalent to 0.52 in the sample of the present study, or if the value of this ratio at LM2 
was more than percentile 65 (100-35) which is equivalent to .56 , there is a high probability of encountering a deep LU in the respective region; 2$) 16.2 \%\left(r^{2}=0.162\right)$ and $20 \%\left(r^{2}=0.200\right)$ of variation in LU angulation is explained by variation in the alveolar process height at LM1 and LM2 site, respectively. This also means that if the value of the alveolar process height at the LM1 site was less than percentile 16.2 which is equivalent to $21.5 \mathrm{~mm}$, or if the value of this height at LM2 was less than percentile 20 which is equivalent to $19.7 \mathrm{~mm}$, there is a high probability of encountering a deep LU in the respective region; 3$) 5.2 \%\left(r^{2}=0.052\right)$ and $7.3 \%\left(r^{2}=0.073\right)$ of variation in LU angulation is explained by variation in the distance from the apical region of dental alveoli to the superior margin of the IAN canal at LM1 and LM2 site, respectively. This also means that if the value of this distance at the LM1 site was less than percentile 5.2 which is equivalent to $0.4 \mathrm{~mm}$, or if the value of this distance at LM2 was less than percentile 7.3 which is equivalent to $0.1 \mathrm{~mm}$, there is a high probability of encountering a deep LU in the respective region; and 4) $5 \%\left(r^{2}=0.050\right)$ and $15.2 \%\left(r^{2}=0.152\right)$ of variation in LU angulation is explained by variation in the alveolar process bucco-lingual width at LM1 and LM2 site, respectively. This also means that if the value of this width at the LM1 site was more than percentile 95 (100-5) which is equivalent to $13.4 \mathrm{~mm}$, or if the value of this width at LM2 was more than percentile 84.8 (100-15.2) which is equivalent to $13.3 \mathrm{~mm}$, there is a high probability of encountering a deep $\mathrm{LU}$ in the respective region (Table III).

Table I. Correlations of the measured variables at the LM1 site $(n=102)$.

\begin{tabular}{lcccccc}
\hline & & APH6 & BLW6 & BLW6/APH6 & APXtoIAN6 & LUA6 \\
\hline APH6 & $\mathrm{R}$ & 1 & & & & \\
BLW6 & $\mathrm{R}$ & .077 & 1 & & & \\
BLW6/APH6 & $\mathrm{R}$ & $-.629^{* *}$ & $.718^{* *}$ & 1 & & \\
APXtoIAN6 & $\mathrm{R}$ & $.700^{* *}$ & -.037 & $-.512^{* *}$ & 1 & \\
LUA6 & $\mathrm{R}$ & $-.403^{* *}$ & $.224^{*}$ & $.454^{* *}$ & $-.227^{*}$ & 1 \\
\hline
\end{tabular}

*Correlation is significant at the 0.05 level (2-tailed); **Correlation is significant at the 0.01 level (2-tailed); R: Pearson's correlation coefficient; APH6: alveolar process height at the LM1 site; BLW6: bucco-lingual width of the alveolar process at the LM1 site; APXtoIAN6: the distance from the apical region of dental alveolus to the superior margin of the IAN canal at the LM1 site; LUA6: lingual undercut angulation at the LM1 site.

Table II. Correlations of the measured variables at the LM2 site $(n=112)$.

\begin{tabular}{|c|c|c|c|c|c|c|}
\hline & & APH7 & BLW7 & BLW7/APH7 & APXtoIAN7 & LUA7 \\
\hline APH7 & $\mathrm{R}$ & 1 & & & & \\
\hline BLW7 & $\mathrm{R}$ & .012 & 1 & & & \\
\hline BLW7/APH7 & $\mathrm{R}$ & $-.628 * *$ & $.761 * *$ & 1 & & \\
\hline APXtoIAN7 & $\mathrm{R}$ & $.527^{* *}$ & -.177 & $-.453 * *$ & 1 & \\
\hline LUA7 & $\mathrm{R}$ & $-.447 * *$ & $.390 * *$ & $.592 * *$ & $-.271 * *$ & 1 \\
\hline
\end{tabular}

**Correlation is significant at the 0.01 level (2-tailed); R: Pearson's correlation coefficient; APH7: alveolar process height at the LM2 site; BLW7: bucco-lingual width of the alveolar process at the LM2 site; APXtoIAN7: the distance from the apical region of dental alveolus to the superior margin of the IAN canal at the LM2 site; LUA7: lingual undercut angulation at the LM2 site.

Table III. Cut-off points for the predictors of lingual undercut depth at both LM1 and LM2 sites.

\begin{tabular}{ll}
\hline Predictor & Cut-off point \\
\hline BLW6/APH6 & More than 0.52 \\
BLW7/APH7 & More than 0.56 \\
APH6 & Less than $21.5 \mathrm{~mm}$ \\
APH7 & Less than $19.7 \mathrm{~mm}$ \\
APX to IAN6 & Less than $0.4 \mathrm{~mm}$ \\
APX to IAN7 & Less than $0.1 \mathrm{~mm}$ \\
BLW6 & More than $13.4 \mathrm{~mm}$ \\
BLW7 & More than $13.3 \mathrm{~mm}$ \\
\hline
\end{tabular}

BLW6: bucco-lingual width of the alveolar process at the LM1 site; BLW7: bucco-lingual width of the alveolar process at the LM2 site; APH6: alveolar process height at the LM1 site; APH7: alveolar process height at the LM2 site; APX to IAN6: the distance from the apical region of dental alveolus to the superior margin of the IAN canal at the LM1 site; APX to IAN7: the distance from the apical region of dental alveolus to the superior margin of the IAN canal at the LM2 site. 
ABUKARAKY, A. E.; ALHADIDI, A.; HAMDAN, A. A. S.; HAMDAN, M. \& ALSOLEIHAT, F. Morphometric predictors of lingual undercut depth in the posterior mandible and their relevance to immediate dental implant insertion: Recommendations for CBCT. Int. J. Morphol., 37(3):947-952, 2019.

\section{DISCUSSION}

LU is a common finding in the mandible, with its presence and severity having been investigated in the literature (Herranz-Aparicio et al.; Alrahaimi \& Venkatesh; Yoon et al.). LPP in the posterior mandibular region is likely to result in nerve injury if the perforation site is above the mylohyoid ridge where the lingual nerve is commonly located (Chan et al., 2011). On the other hand, perimandibular vessels usually found beneath the mylohyoid muscle running at a mean horizontal distance of $2 \mathrm{~mm}$ at LM2 area, LPP at this area may cause injury to these vessels and may lead serious bleeding (Mardinger et al., 2007). LPP in the posterior mandibular region with implant exposure to the oral cavity might also be a source of persistent inflammation and infection. If left unattended, the infection may spread to the para- and retro-pharyngeal spaces. This may result in serious and life-threatening complications such as: mediastinitis, upper airway obstruction, aneurysm and possible rupture of the internal carotid artery, or thrombus formation in the internal jugular vein leading to septic pulmonary embolism (Greenstein et al., 2008a,b).

Risk of LPP during implant insertion in the posterior mandible might be avoided or reduced if clinicians have anticipated the presence and severity of LU. Increased alveolar process width and short distance from root apices of posterior teeth to IAN canal were reported in to be related to the presence and severity of LU (Huang et al.; de Souza et al.). Our current study confirm these results, however, the findings reported by the previous studies were dependent on data derived from CBCTS only. In the current study, with the exception of the ridge width, data were derived from OPGs and co- related with the CBCT findings. An interesting finding in our study that might have an important practical value in anticipating LUs during implant insertion in the posterior mandible is the correlation between alveolar process height at LM1 and LM2, as measured on OPGs, and the LU angulation at LM1 and LM2, respectively. Although these correlations are moderate, they are statistically significant, and have been shown in this study to be more strongly correlated with LU angulation than the width of the alveolar process and the distance from the apical region of dental alveoli to the superior margin of the IAN canal at both LM1 and LM2 sites. Moreover, the ratio between the alveolar process width and height was found to be the strongest predictor of LU angulation at both LM1 $(\mathrm{r}=.454)$ and LM2 ( $\mathrm{r}=.592)$ sites.

As the width of the alveolar process might be assessed clinically with reasonable accuracy (Castro-Ruiz et al., 2015) and other predictors are measured on OPGs, and based on the results of the present study, the authors suggest that clinicians might be able anticipate the depth of LU from data extracted by OPGs especially when combined with clinical examination. Such data might guide clinicians to order a CBCT prior to implant insertion in the posterior mandible when deep LU is predicted and hence potential complications might be avoided. It is also noteworthy to mention that clinical evaluation might detect but may not lead to the complete image of the lingual undercut, especially in the under-floor parts of mouth (Parnia et al., 2010). Therefore, clinical palpation alone is not absolutely reliable in evaluating the presence of lingual undercut and the risk of lingual plate perforations. The authors also would like to highlight that the analyses in the present study are based on data derived from dentate sites; thus the results are solely applicable to immediate implant patients as the bone resorption following tooth extraction is rather unpredictable. The results of this study are of great significance to practitioners who do not have access to CBCT imaging, and/or to situations where there is high concern to avoid extra radiation dose to the patient. At a minimum, the OPG could be correlated with clinical data, for example depth of the lingual undercut, to determine in what circumstances the CBCT need not be done.

\section{CONCLUSIONS}

Within the limitations of the study and as explained earlier in the results, the LU predictors could be summarized and in a descending order according to strength as follows:

1. The ratio of the alveolar width and height at the LM1 site is more than .52 or more than .56 at the LM2 site.

2. The alveolar process height measured on the OPG at the LM1 and LM2 sites is less than $21.5 \mathrm{~mm}$ and $19.7 \mathrm{~mm}$, respectively.

3. The distance from the apical region of dental alveoli to the superior margin of the IAN canal measured on the OPG is less than $0.4 \mathrm{~mm}$ and $0.1 \mathrm{~mm}$ at the LM1 and LM2 sites, respectively.

4. The bucco-lingual width of the alveolar process is more than $13.4 \mathrm{~mm}$ and $13.3 \mathrm{~mm}$ at the LM1 and LM2 sites, respectively.

\section{ACKNOWLEDGEMENTS}

The authors would like to thank the patients for their participation in this study. This research was conducted at the School of Dentistry of the University of Jordan. 
ABUKARAKY, A. E.; ALHADIDI, A.; HAMDAN, A. A. S.; HAMDAN, M. \& ALSOLEIHAT, F. Predictores morfométricos de la profundidad dela «udercut» lingual en la parte posterior de la mandíbula y su relevancia para la inserción inmediata de implantes dentales: Recomendaciones para la CBCT. Int. J. Morphol., 37(3):947-952, 2019.

RESUMEN: El socavado lingual profundo (SLU) se encuentra comúnmente en la porción posterior de la mandíbula y es considerado un factor de riesgo en los implantes dentales. En este estudio, investigamos el valor de los datos extraídos de los OPG para predecir la profundidad del SLU. Dichos predictores podrían ser valiosos para reducir la posibilidad de perforación de la placa lingual (PPL) recomendando CBCT antes de la inserción del implante dental cuando se anticipa un SLU. El objetivo consistió en evaluar las siguientes variables como posibles predictores de profundidad de SLU: 1) altura del proceso alveolar (medida en OPG), 2) ancho del proceso alveolar (medido en CBCT) y 3) la distancia desde la región apical de los alvéolos dentales al margen superior del canal IAN (medido en OPG). Se utilizaron 128 CBCT y las OPG correspondientes de mandíbulas de 128 pacientes ( 70 mujeres, 58 hombres; rango de edad $=18-87$ años, edad media $=45,8$ años, $S D=17,0$ años). Sólo se consideraron los sitios dentados de los primeros molares inferiores (LM1) y los segundos molares inferiores (LM2). Se encontraron cuatro predictores de profundidad de SLU, el más fuerte fue la relación entre el ancho del proceso alveolar (que podría evaluarse clínicamente) y la altura del proceso alveolar medida en OPG $(\mathrm{r}=0,454$ en el sitio LM1, $r=0,592$ en el sitio LM2). Los predictores derivados de las mediciones de OPG podrían ser valiosos para anticipar la profundidad de SLU y podrían ser más valiosos cuando se combinan con el ancho del proceso alveolar (que podría evaluarse clínicamente). Recomendamos considerar los factores predictivos sugeridos para evaluar la necesidad de CBCT antes de la inserción inmediata del implante dental en la porción posterior de la mandíbula.

PALABRAS CLAVE: Recorte lingual; Mandíbula; Implantes dentales; Tomografía computarizada de haz cónico; Perforación de la placa lingual.

\section{REFERENCES}

Alrahaimi, S. F. \& Venkatesh, E. Localization of mandibular canal and assessment of the remaining alveolar bone in posterior segment of the mandible with single missing tooth using cone-beam computed tomography: a cross sectional comparative study. J. Korean Assoc. Oral Maxillofac. Surg., 43(2):100-5, 2017.

Annibali, S.; Ripari, M.; La Monaca, G.; Tonoli, F. \& Cristalli, M. P. Local accidents in dental implant surgery: prevention and treatment. Int. J. Periodontics Restorative Dent., 29(3):325-31, 2009.

Berberi, A.; Le Breton, G.; Mani, J.; Woimant, H. \& Nasseh, I. Lingual paresthesia following surgical placement of implants: report of a case. Int. J. Oral Maxillofac. Implants, 8(5):580-2, 1993.

Castro-Ruiz, C. T.; Noriega, J. \& Guerrero, M. E. Validity of ridge mapping and cone beam computed tomography in dental implant therapy. J. Indian Soc. Periodontol., 19(3):290-3, 2015.

Chan, H. L.; Brooks, S. L.; Fu, J. H.; Yeh, C. Y.; Rudek, I. \& Wang, H. L. Crosssectional analysis of the mandibular lingual concavity using cone beam computed tomography. Clin. Oral Implants Res., 22(2):201-6, 2011.

Chrcanovic, B. R.; de Carvalho Machado, V. \& Gjelvold, B. Immediate implant placement in the posterior mandible: A cone beam computed tomography study. Quintessence Int., 47(6):505-14, 2016.

Clark, D.; Barbu, H.; Lorean, A.; Mijiritsky, E. \& Levin, L. Incidental findings of implant complications on postimplantation CBCTs: A cross-sectional study. Clin. Implant Dent. Relat. Res., 19(5):776-82, 2017.

Dau, M.; Edalatpour, A.; Schulze, R.; Al-Nawas, B.; Alshihri, A. \& Kämmerer, P. W.
Presurgical evaluation of bony implant sites using panoramic radiography and cone beam computed tomography-influence of medical education. Dentomaxillofac. Radiol., 46(2):20160081, 2017.

de Souza, L. A.; Souza Picorelli Assis, N. M.; Ribeiro, R. A.; Pires Carvalho, A. C. \& Devito, K. L. Assessment of mandibular posterior regional landmarks using cone-beam computed tomography in dental implant surgery. Ann. Anat., 205:539, 2016.

Givol, N.; Chaushu, G.; Halamish-Shani, T. \& Taicher, S. Emergency tracheostomy following life-threatening hemorrhage in the floor of the mouth during immediate implant placement in the mandibular canine region. J. Periodontol., 71(12):1893$5,2000$.

Greenstein, G.; Cavallaro, J. \& Tarnow, D. Practical application of anatomy for the dental implant surgeon. J. Periodontol., 79(10):1833-46, 2008 b.

Greenstein, G.; Cavallaro, J.; Romanos, G. \& Tarnow, D. Clinical recommendations for avoiding and managing surgical complications associated with implant dentistry: a review. J. Periodontol., 79(8):1317-29, 2008a.

Herranz-Aparicio, J.; Marques, J.; Almendros-Marqués, N. \& Gay-Escoda, C. Retrospective study of the bone morphology in the posterior mandibular region. Evaluation of the prevalence and the degree of lingual concavity and their possible complications. Med. Oral Patol. Oral Cir. Bucal, 21(6):e731-6, 2016.

Huang, R. Y.; Cochran, D. L.; Cheng, W. C.; Lin, M. H.; Fan, W. H.; Sung, S. E.; Mau, L. P.; Huang, P. H. \& Shieh, Y. S. Risk of lingual plate perforation for virtual immediate implant placement in the posterior mandible: A computer simulation study. J. Am. Dent. Assoc., 146(10):735-42, 2015.

Kalpidis, C. D. \& Setayesh, R. M. Hemorrhaging associated with endosseous implant placement in the anterior mandible: a review of the literature. J. Periodontol., 75(5):631-45, 2004

Lang, T. A. \& Secic, M. How to Report Statistics in Medicine. Annotated Guidelines for Authors, Editors, Reviewers. $2^{\text {nd }}$ ed. Philadelphia, American College of Physicians, 2006.

Leong, D. J.; Chan, H. L.; Yeh, C. Y.; Takarakis, N.; Fu, J. H. \& Wang, H. L. Risk of lingual plate perforation during implant placement in the posterior mandible: a human cadaver study. Implant Dent., 20(5):360-3, 2011.

Mardinger, O.; Manor, Y.; Mijiritsky, E. \& Hirshberg, A. Lingual perimandibular vessels associated with life-threatening bleeding: an anatomic study. Int. J. Oral Maxillofac. Implants, 22(1):127-31, 2007.

Parnia, F.; Fard, E. M.; Mahboub, F.; Hafezeqoran, A. \& Gavgani, F. E. Tomographic volume evaluation of submandibular fossa in patients requiring dental implants. Oral Surg. Oral Med. Oral Pathol. Oral Radiol. Endod., 109(1):e32-6, 2010.

Quirynen, M.; Mraiwa, N.; van Steenberghe, D. \& Jacobs, R. Morphology and dimensions of the mandibular jaw bone in the interforaminal region in patients requiring implants in the distal areas. Clin. Oral Implants Res., 14(3):280-5, 2003.

Sener, E.; Onem, E.; Akar, G. C.; Govsa, F.; Ozer, M. A.; Pinar, Y.; Mert, A. \& Baksi Sen, B. G. Anatomical landmarks of mandibular interforaminal region related to dental implant placement with 3D CBCT: comparison between edentulous and dental mandibles. Surg. Radiol. Anat., 40(6):615-23, 2018.

Tepper, G.; Hofschneider, U. B.; Gahleitner, A. \& Ulm, C. Computed tomographic diagnosis and localization of bone canals in the mandibular interforaminal region for prevention of bleeding complications during implant surgery. Int. J. Oral Maxillofac. Implants, 16(1):68-72, 2001.

Yoon, T. Y.; Patel, M.; Michaud, R. A. \& Manibo, A. M. Cone beam computerized tomography analysis of the posterior and anterior mandibular lingual concavity for dental implant patients. J. Oral Implantol., 43(1):12-8, 2017.

\section{Corresponding author:}

Dr. Firas Alsoleihat

Associate Professor

Department of Conservative Dentistry

School of Dentistry

The University of Jordan

Amman 11942

JORDAN

Email: firas.alsoleihat@ju.edu.jo

Received: 08-02-2019

Accepted: 12-03-2019 